\title{
A blurring of life-history lines: Immune function, molt and reproduction in a highly stable environment
}

\author{
Loren Merrill $^{\mathrm{a}, *}$, Paulina L. González-Gómez ${ }^{\mathrm{b}}$, Vincenzo A. Ellis ${ }^{\mathrm{c}}$, Iris I. Levin ${ }^{\text {d,e }}$, Rodrigo A. Vásquez ${ }^{\mathrm{f}}$, \\ John C. Wingfield ${ }^{g}$ \\ a Illinois Natural History Survey, University of Illinois, Urbana-Champaign, IL 61820, USA \\ ${ }^{\mathrm{b}}$ Instituto de Filosofia y Ciencias de la Complejidad (IFICC), Santiago, Chile \\ ' Department of Biology, University of Missouri, St. Louis, MO 63121, USA \\ ${ }^{\mathrm{d}}$ Department of Biology, Grinnell College, Grinnell, IA 50112, USA \\ ${ }^{\mathrm{e}}$ Department of Ecology and Evolutionary Biology, University of Colorado at Boulder, Boulder, CO 80309, USA ${ }^{1}$ \\ ${ }^{\mathrm{f}}$ Instituto de Ecología y Biodiversidad, IEB, Universidad de Chile, Santiago, Chile \\ ${ }^{\mathrm{g}}$ University of California Davis, Davis, CA 95616, USA
}

\section{A R T I C L E I N F O}

\section{Article history:}

Received 10 October 2014

Revised 26 January 2015

Accepted 14 February 2015

Available online 21 February 2015

\section{Keywords:}

Bacteria-killing ability

Corticosterone

Hypothalamo-pituitary-adrenal axis

Rufous-collared sparrow

Trade-off

Zonotrichia

\begin{abstract}
A B S T R A C T
Rufous-collared sparrows (Zonotrichia capensis peruviensis) from valleys in the Atacama Desert of Chile, live in an extremely stable environment, and exhibit overlap in molt and reproduction, with valley-specific differences in the proportion of birds engaged in both. To better understand the mechanistic pathways underlying the timing of life-history transitions, we examined the relationships among baseline and stress-induced levels of corticosterone (CORT), testosterone, and bacteria-killing ability of the blood plasma (BKA), as well as haemosporidian parasite infections and the genetic structure of two groups of sparrows from separate valleys over the course of a year. Birds neither molting nor breeding had the lowest BKA, but there were no differences among the other three categories of molt-reproductive stage. BKA varied over the year, with birds in May/June exhibiting significantly lower levels of BKA than the rest of the year. We also documented differences in the direction of the relationship between CORT and BKA at different times during the year. The direction of these relationships coincides with some trends in molt and reproductive stage, but differs enough to indicate that these birds exhibit individual-level plasticity, or population-level variability, in coordinating hypothalamo-pitui tary-adrenal axis activity with life-history stage. We found weak preliminary evidence for genetic differentiation between the two populations, but not enough to indicate genetic isolation. No birds were infected with haemosporidia, which may be indicative of reduced parasite pressure in deserts. The data suggest that these birds may not trade off among different life-history components, but rather are able to invest in multiple life-history components based on their condition.
\end{abstract}

c) 2015 Elsevier Inc. All rights reserved.

\section{Introduction}

Life-history theory proposes that organisms trade off between competing functions due to resource constraints (Stearns, 1992). The classic example is allocation of resources to current versus future reproduction, and the inherent trade-off between self-maintenance and reproductive effort (Stearns, 1992; Sheldon

\footnotetext{
* Corresponding author at: 1816 S. Oak St., Champaign, IL 61820, USA.

E-mail addresses: loren21@illinois.edu (L. Merrill),plgonzalezgomez@gmail.com (P.L. González-Gómez), vincenzoellis@mail.umsl.edu (V.A. Ellis), Iris.Levin@ colorado.edu (I.I. Levin), rvasquez@uchile.cl (R.A. Vásquez),jcwingfield@ucdavis. edu (J.C. Wingfield).

1 Current address.
}

and Verhulst, 1996; Schmid-Hempel, 2003). Molt and immune function are the best-studied components of self-maintenance in birds. Molt quality influences thermoregulatory capacity (Nilsson and Svensson, 1996; Dawson et al., 2000), flight performance (Swaddle et al., 1996; Echeverry-Galvis and Hau, 2013), and plumage-based signal quality (Smith and Montgomerie, 1991; Serra et al., 2007), all of which have important fitness implications. Immune system function is also an integral factor shaping avian fitness (sensu Combes, 2001; Davison et al., 2008); it determines the ability to inhibit or limit parasite establishment and is responsible for the regulation or elimination of established infections (Davison et al., 2008 and references therein). Together, molt and immune function can have large-scale consequences for future reproductive capacity. 
Molt and immune defenses demand energy and resources (molt: Murphy, 1996; Hoye and Buttemer, 2011; immunity: Klasing, 2004), and there is a large body of work examining pair-wise trade-offs among molt, immunity, and reproduction (e.g., molt-immunity: Moreno-Rueda, 2010; Ellis et al., 2012; molt-reproduction: Barta et al., 2006; Johnson et al., 2012; reproduction-immunity: Deerenberg et al., 1997; Ardia, 2005; Kelly, 2011). There is evidence that most birds undergo seasonal changes in which they invest differentially among these three life-history functions (e.g., Nelson and Demas, 1996; Zera and Harshman, 2001; Wingfield, 2005). For example, most temperate birds exhibit discreet periods of breeding and molt, with molt typically occurring at the conclusion of breeding (Morton, 1992; Barta et al., 2006; Johnson et al., 2012). Immune function can also vary over the annual cycle (Nelson and Demas, 1996; Hegemann et al., 2012; Merrill et al., 2013), as organisms allocate resources between self-maintenance and current reproduction in response to resource limitation, or if parasite pressure changes over the course of the year (John, 1994; Horrocks et al., 2012a).

Organisms also use seasonal cues (e.g., photoperiod, rainfall) to initiate different life-history stages, and these life-history stages are typically regulated, at least in part, by circulating glucocorticoids and androgens (Wingfield, 2005). However, organisms that live in stable environments with little seasonal variation in resource availability, or little change in photoperiod, temperature or rainfall, may not need, or be able, to utilize seasonal cues. In these cases, what factors determine life-history stage, and do organisms exhibit trade-offs among different life-history stages? Birds that do exhibit overlap of multiple life-history stages, such as molt and reproduction, may attempt to reduce the costs of one or both processes. They can do this via reduced molt intensity (Echeverry-Galvis and Hau, 2012), smaller clutches (Foster, 1974), and extended incubation (Ricklefs and Brawn, 2013). However, little work has been conducted on measures of immune function, molt and reproduction concurrently, especially over an entire year. The goal of this study is to understand how birds balance immune function, molt and reproduction in two discrete populations in an environment with little seasonal variation. Additionally, we explore whether population differences might be attributed to differential parasite pressure or population genetic differences.

Previously, we examined the relationships among corticosterone (CORT), testosterone $(\mathrm{T})$, reproduction and molt in rufous-collared sparrows (Zonotrichia capensis peruviensis) over the course of a year in the Atacama Desert of Chile (Gonzalez-Gomez et al., 2013). This desert is the driest and oldest desert on the planet (Hartley et al., 2005) and exhibits very little change in environmental conditions over the year. We studied sparrows living in two valleys (Azapa Canyon and Lluta Canyon) separated by $1000 \mathrm{~m}$ high canyon walls and $25 \mathrm{~km}$ of non-vegetated desert habitat, inhospitable to these birds. We documented most of the birds molting during March and breeding in October, indicating that the birds maintain some semblance of an annual cycle, although many of the sparrows diverge from the general trends. We found individuals molting or breeding year round, as well as individuals engaging in both breeding and molt in every sampling period during the year. We also found that the sparrows in the two valleys exhibited distinct patterns from each other. Among birds engaged in breeding, approximately five times as many birds overlap breeding and molting in Azapa as in Lluta (25\% vs. 6\%, Gonzalez-Gomez et al., 2013). We also found differences in body condition with relatively heavier birds in Azapa than in Lluta in January but the opposite pattern in December. In addition, stress-response levels are significantly higher in Lluta than in Azapa in January. Despite these differences, there were no data on the genetic structure of the two breeding groups to help determine whether the differences between the two sites were due to genetic or environmental reasons. Although $25 \mathrm{~km}$ is a relatively short distance, previous studies have found genetic differences between two populations of $Z$. capensis that live $25 \mathrm{~km}$ apart inhabiting benign environments that theoretically do not represent a dispersal barrier to this species (Moore et al., 2005) as could be the inhospitable Atacama Desert.

Here we expand upon previous work with these birds (Gonzalez-Gomez et al., 2013) and incorporate an aspect of immune function (bacteria-killing ability), prevalence of haemosporidian blood parasite infections, and preliminary data on the genetic structure of the two populations of $Z$. capensis to help better understand the factors that shape how and when these birds allocate resources among multiple life-history stages. We have also included levels of testosterone $(\mathrm{T})$ as well as baseline and stress-induced levels of corticosterone (CORT). In our prior study we examined the relationships between $\mathrm{T}$ and life-history stage as well as between both baseline and stress-induced CORT levels and life-history stage to determine if the hormones are associated with regulation of life-history trade-offs in this minimally seasonal environment. We found that CORT varied with time of year and with life-history stage in these birds and that during the period in which most birds were engaged in molt to some degree (March), birds down-regulated their stress-response (Gonzalez-Gomez et al., 2013). Birds not engaging in molt at this time, however, still exhibited this down-regulation. Other populations of $Z$. capensis undergo molt at different times during the year (e.g., May/June for those in the nearest study locale, Lima, Peru; Davis 1971), suggesting that sparrows in these valleys may be fine-tuned to local conditions. If this is the period of peak molt for the population, perhaps down-regulation of the stress response has been set to some circannual (e.g., photoperiod) or environmental cue (e.g., slight variation in stream flow or food availability), but the actual molt stage has become decoupled from hypothalamopituitary-adrenal (HPA)-axis activity and depends on other factors such as reproductive stage, and/or individual condition.

In the current study we used BKA as a functional assessment of the birds' immune defenses against a bacterial pathogen. We have previously found BKA to vary seasonally in other species (e.g., Icterids, Merrill et al., 2013) and it may be traded-off against molt (Ellis et al., 2012, but see Buehler et al., 2008) and reproductive effort (Merrill et al., 2013). In addition, we have found BKA to be positively linked to baseline CORT, and negatively linked to stress-induced CORT levels (Merrill et al., 2012, 2014), and T levels (Merrill et al., 2015) in blackbirds. We were interested in whether T or CORT were linked to regulation of immune function in these sparrows, and if so, in what manner.

For parasite assessment we screened for both Plasmodium and Haemoproteus blood parasites because these are known to infect Z. capensis in South America (Durrant et al., 2006; Merino et al., 2008; Jones et al., 2013) and are capable of exerting strong selective pressure on their bird hosts (Allander, 1997; Ots and Hõrak, 1998; Atkinson et al., 2001; Knowles et al., 2009; Martinez-de la Puente et al., 2010; Lachish et al., 2011; Watson, 2013). However, animals in desert environments may have lower prevalence and intensity of both endo and ectoparasites (Little and Earlé, 1995; Tella et al., 1999; Moyer et al., 2002; Valera et al., 2003; Horrocks et al., 2012b), and could be under reduced parasite pressure. For example, recent work examining blood parasites in the cinereous conebill (Conirostrum cinereum) in the same region of the Atacama Desert found one trypanosome infection and no other blood parasites among the 30 individuals assessed (Martinez et al. unpublished data).

Previously, we found that body condition (residuals of body mass over tarsus) in these sparrows varied over time, and that there were differences among sampling periods and localities in the proportion of birds engaging in molt and/or reproduction 
(Gonzalez-Gomez et al., 2013). These results suggest that birds do not have unlimited access to resources, and/or that they experience constraints in processing, producing, or utilizing energy. We therefore predicted that birds would still be somewhat resource limited and would exhibit trade-offs between immune function and other life-history stages. We predicted that birds engaging in both molt and reproduction would exhibit the lowest levels of BKA, and that seasonal variation in molt and reproductive life-history stages would be reflected in seasonal variance in BKA. We also predicted that baseline CORT would be positively linked to BKA, but that BKA would not covary with T due to the stable nature of $T$ in these birds over the annual cycle.

Regarding haemosporidian infections, we compared prevalences between the two sites to examine whether haemosporidian blood parasite infections are a factor influencing the ability of birds to invest in multiple life-history stages simultaneously. We predicted that the overall prevalence of blood parasites would be low due to the challenging environment surrounding the two sites.

This study also provided us with an opportunity to examine the relative strength of the relationships among these life-history strategies, allowing us to examine if molt or reproduction are traded off more strongly against BKA. We predicted that the strength of the trade-off would be greater between reproduction and BKA than between molt and BKA due to the more flexible nature of molt (sensu Moreno, 2004), and the long and irregular molt patterns we observed in this site (Gonzalez-Gomez et al., 2013). Finally, we expected that birds from the two valleys (Azapa and Lluta) would exhibit distinct genetic structure as a result of the lack of opportunities for dispersal and interbreeding between populations due to the inhospitable nature of the surrounding habitat.

\section{Methods}

\subsection{Species, study site, and sample collection}

In brief, $Z$. capensis are socially monogamous and exhibit bi-parental care (Chapman, 1940; Miller and Miller, 1968). They are primarily granivorous, but will consume arthropods and fruits (Novoa et al., 1996). They are distributed from southeastern Mexico to the southernmost tip of South America. They occupy a diversity of habitats including urbanized areas, chaparral, forest edge, and alpine meadows (Estades and Temple, 1999; Class et al., 2011; Maldonado et al., 2012).

The two study sites are located in the Atacama Desert in northern Chile: (i) Azapa valley $\left(18^{\circ} 30^{\prime} 54.89^{\prime \prime} \mathrm{S}, 70^{\circ} 11^{\prime} 35.09^{\prime \prime} \mathrm{W}, 260 \mathrm{~m}\right.$ above sea level) and (ii) Lluta valley $\left(18^{\circ} 24^{\prime} 40.39^{\prime \prime} \mathrm{S}, 70^{\circ} 14^{\prime} 10.79^{\prime \prime}\right.$ $\mathrm{W}, 225 \mathrm{~m}$ above sea level). This site has been described as one of the most climatically stable locations on earth with minimal variability in both temperature and rainfall year-round (Torres and Acevedo, 2008). Daily maximum and minimum temperatures averaged $23.29 \pm 2.63{ }^{\circ} \mathrm{C}$ and $18.79 \pm 1.84{ }^{\circ} \mathrm{C}$ over the course of this year-long study. Also, in the last 50 years the average of rainfall is $0.5 \mathrm{~mm}$ per year (Torres and Acevedo, 2008). The major change in this environment occurs every 4-5 years during ENSO events, when the flow of streams running from Los Andes to the Pacific Ocean increases roughly 0.7 times. Overall this is a small change in comparison with other xeric environments in the same region (Gutiérrez et al., 2010).

For this work, we examined BKA, blood parasite prevalence, CORT, $T$ and population genetic structure from a randomly selected subset of individuals used in the companion study (Gonzalez-Gomez et al., 2013). Sampling occurred for a 1 week period approximately every 2 months from October 2010 to October 2011; October 23-30 2010, December 9-17 2010, January 20-27 2011, March 9-19 2011, May 27-June 5 2011,
October 20-27 2011. We lumped the data from the two October sampling periods together as we did in the previous study because there were no differences between them for hormones, condition, life-history stage (Gonzalez-Gomez et al., 2013), or in BKA (T-test: $t_{1,16}=0.304, P=0.77$ ). Birds were captured between 0700 and 1100 using mist-nets with no playback of recorded songs, and a blood sample was collected within $3 \mathrm{~min}$ of capture (i.e., since the bird hit the net) to assess baseline CORT levels and BKA, within $10 \mathrm{~min}$ of capture for $\mathrm{T}$, and $30 \mathrm{~min}$ after morphometric measurements for stress-induced CORT levels. Blood was collected from the alar vein using a 26 gauge needle and heparinized capillary tubes, and was placed on ice for a maximum of $4 \mathrm{~h}$ before centrifuging. Plasma was then removed and frozen until analysis. Hematocrit was also frozen until analysis. Morphometric data were measured following blood collecting, and birds were banded with numerical metal bands. Birds were placed in a cloth bag for the $30 \mathrm{~min}$ "stress" period following morphometric data collection (see Breuner et al., 1999 for details on stress-induced CORT response protocol).

Hormones were assessed using direct radioimmunoassays (Wingfield et al., 1992), and were extracted from the plasma using freshly re-distilled dichloromethane. Samples were reconstituted in PBS with gelatin and were then run in duplicate. A total of three $\mathrm{T}$ assays (intra-assay variation $8.4-13.3 \%$, inter-assay variation $11.5 \%$, recovery of ${ }^{3} \mathrm{H}$-labeled T: $80.93 \% \pm 0.93 \%$ ) and seven CORT assays (intra-assay variation $7.2-11.8 \%$, inter-assay variation $9.48 \%$, recovery of ${ }^{3} \mathrm{H}$-labeled CORT: $82.39 \% \pm 0.46 \%$ ) were run by P.L.G.-G.

Molt status (yes/no) was determined by assessing the presence or absence of feathers in molting condition (i.e., missing feathers, feathers growing) in flight feathers (primaries, secondaries, coverts or retrices), or greater than $20 \%$ of body molt. Molt intensity was assessed as the number of regions with growing or missing feathers. Molt asymmetry was categorized (yes/no) by the presence of different number or position of growing or missing wing feathers (i.e., primary 2 and 3 in the right wing and primary 6 in left wing). Reproductive status was determined by the presence or absence of a cloacal protuberance in males (reproductively active males $=\mathrm{CP}>5 \mathrm{~mm}$; Miller, 1959), and the presence or absence of a brood patch in females (Addis et al., 2011). We looked at whether molt intensity or asymmetry had an effect on BKA, but found no evidence for this (molt intensity: ANOVA; $F_{3,89}=1.44$, $\mathrm{Eta}^{2}=0.048, P=0.24$; molt asymmetry: BKA in birds showing asymmetry $-0.062 \pm 0.17$ vs. BKA in birds showing non-asymmetric molt $-0.1050 \pm 0.15$, mean \pm se, T-test: $\left.t_{1,19}=0.598, P=0.56\right)$, so we lumped all molting birds together.

\subsection{Bacteria-killing assay}

In this assay, bacteria-killing is primarily complement dependent (Matson et al., 2006; Merrill unpublished data), and complement proteins are an important part of the constitutive innate response because they can opsonize or lyse invading cells (Esser, 1994). They also can target antigen to lymphoid organs, and lower the threshold for B-cell activation (Ochsenbein and Zinkernagel, 2000), thus providing a link between the innate and acquired arms of the immune system. Methods for the assay were derived from Matson et al. (2006), Millet et al. (2007) and Morrison et al. (2009), and all aspects of the assay in which sample or media were exposed to the air were carried out in a sterile hood. In brief, we added $5 \mu \mathrm{L}$ of plasma to a combination of $\mathrm{CO}_{2}$-independent media (Gibco, Invitrogen) $+4 \mathrm{mM}$ L-glutamine $(90 \mu \mathrm{L})$, and the Escherichia coli (ATCC \# 8739) bacterial broth $(10 \mu \mathrm{L})$, incubated the solution for $20 \mathrm{~min}$ at $40^{\circ} \mathrm{C}$, then pipetted out $50 \mu \mathrm{L}$ in duplicate onto agar plates which were then incubated overnight at $37^{\circ} \mathrm{C}$. The number of bacteria colonies was counted the following day and compared 
to control plates in which the bacterial broth and $95 \mu \mathrm{L}$ of PBS were incubated together without any plasma. Killing capacity was determined by subtracting the mean number of colonies for a bird's two plates from the mean number of control colonies, and then dividing that by the control mean. We collected enough blood to run BKA only for baseline levels ( $<3$ min of capture) due to blood collecting limitations, so we do not have BKA that corresponds to the stress-induced CORT samples.

\subsection{Molecular analyses}

\subsubsection{DNA extraction}

Packed red blood cells were shipped on dry ice to the laboratory. We thawed the packed red blood cells and added ca. $20 \mu \mathrm{L}$ of red blood cells to $300 \mu \mathrm{L}$ lysis buffer (Longmire et al., 1997). We then incubated the samples at $60^{\circ} \mathrm{C}$ overnight with $5 \mu \mathrm{L}$ of $20 \mathrm{mg} / \mathrm{ml}$ proteinase K solution (MidSci cat\# IB05406). We extracted genomic DNA from the samples using a standard ammonium acetate-isopropanol protocol (Svensson and Ricklefs, 2009).

\subsubsection{Parasite screening}

We performed two PCR protocols for each sample to screen for avian haemosporidian blood parasites of the genera Plasmodium and Haemoproteus (order Haemosporida). The first is designed to amplify a $154 \mathrm{bp}$ fragment of rRNA-coding parasite mitochondrial DNA (Fallon et al., 2003). The second protocol is a nested PCR designed to amplify a $552 \mathrm{bp}$ fragment of the parasite cytochrome b gene (Fecchio et al., 2013). Details of both protocols can be found in Fecchio et al. (2013).

\subsubsection{Population genetic structure}

Birds for which we had evidence of breeding were used to assess population genetic structure between Azapa and Lluta valleys. Details on marker selection, universal tagging methods and PCR reaction conditions can be found in the supplement. Amplification was checked on a $1 \%$ agarose gel, and samples were run on an Applied Biosystems $3730 \times 1$ DNA analyzer at the Iowa State DNA Facility in multiplex reactions using GS500(-250)LIZ size standard (Applied Biosystems). Multiplex I included Gf01, Gf06 (Petren, 1998), Mme12 (Jeffery et al., 2001), and Lox1 (Piertney et al., 1998) and multiplex II included G03, F11, E11, and C02 (Poesel et al., 2009).

Genemapper v.5 (Applied Biosystems) software was used to analyze allele sizes. Genotypes were scored manually, roughly $10 \%$ of the total samples were re-amplified and genotypes from the original template DNA at all of the loci that were included in the analyses, and roughly one-third of all homozygotes were re-run to ensure we were not incorrectly assigning genotypes due to allelic dropout.

Deviations from Hardy-Weinberg equilibrium (HWE) were tested for each locus with allele randomizations within population (1000 permutations) and for both populations (10,000 permutations) in FSTAT v.2.9.3.2 (Goudet, 2001). Genetic diversity (Nei, 1972) for each locus within population was quantified using FSTAT and HP-RARE (Kalinowski, 2005) was used to calculate rarefied allelic richness per population-locus combination. We tested for linkage disequilibrium in Arlequin v.3.5.1.3 (Excoffier and Lischer, 2010) and checked for the presence of null alleles using ML-NullFreq (Kalinowski, http://www.montana.edu/kalinowski/ Software/MLNullFreq.htm). An $F_{\mathrm{ST}}$ value between the two populations was calculated in Arlequin, as well as estimates of genetic variation partitioned within and between populations using a hierarchical Analysis of Molecular Variance (AMOVA). Genotype clustering was evaluated using a Bayesian method implemented in STRUCTURE v.2.3.3 (Pritchard et al., 2000). The most probable number of populations, $k$, was determined using the second order rate of change in posterior probabilities between runs of different $k$ as described in Evanno et al. (2005) and performed using STRUCTURE-harvester (Earl and vonHoldt, 2011). We performed three runs per $k(k=1-3)$ using the locprior setting, the admixture model, correlated allele frequencies, and a burn-in of 200,000 cycles followed by 500,000 additional cycles. See Supplemental material for additional details.

\subsection{Statistical analyses}

We collected BKA data for 96 adult sparrows, one of which was an outlier that was removed from all analyses. Removal did not qualitatively impact the results, and the outlier is depicted in Figs. 1 and 3 for visual reference. Three other individuals were removed from analyses because we were unable to determine their sex. Due to sample limitations we had BKA data for only two birds in January, so we also removed them from the analyses. We decided to remove them rather than lump them with December because in our previous study we found that there were differences between these sampling periods in some hormone and life-history stage parameters. Of the remaining 90 birds, 38 were from Azapa and 52 from Lluta. From these samples we had T data for 39 birds (26 males, 13 females), and baseline and stress-induced CORT data for 48 birds ( 28 males, 20 females). We created a category ("stage") to delineate a bird's life-history stage in which the bird was designated as engaging in "no molt:no reproduction" $(N=13)$, "molt:no reproduction" $(N=32)$, "no molt:reproduction" $(N=32)$, and "molt:reproduction" $(N=14)$.

We examined the relationship between BKA and the birds' life-history stage by running general linear models with life-history stage, sex, location, month, body condition (residuals of the regression between tarsus length and body mass) as fixed

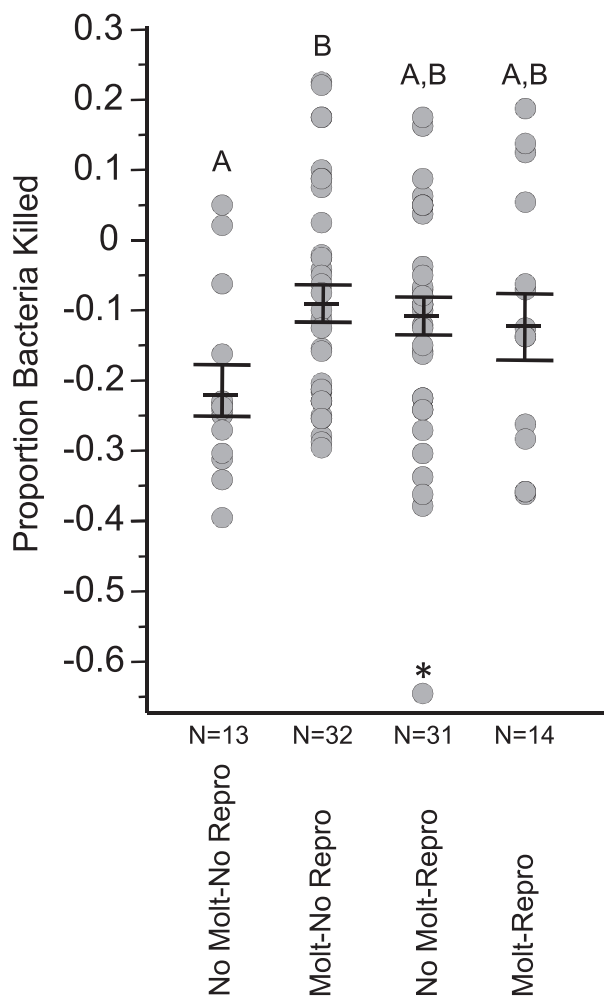

Fig. 1. Bacteria-killing ability (BKA) of Zonotrichia capensis blood plasma by lifehistory stages. Birds were categorized based on their molt status (molt:no molt) and reproductive status (reproduction:no reproduction). Categories with different letters are significantly different based on post hoc Tukey's HSD. Bars represent mean and standard errors. The data point with the asterisk is a statistical outlier and is not included in analyses or sample sizes denoted. 
effects, the interactions between sex and life-history stage, and between body condition and life-history stage, and BKA as the dependent variable. We were unable to run the interactions between month and life-history stage due to sample size limitations. We used Tukey's HSD for post hoc tests of the least squares means to compare significant terms.

To examine the relationships between circulating hormones ( $T$, and baseline and stress-induced CORT) and BKA, we ran separate models for each hormone variable. From previous work we know that for these birds, CORT levels vary by month, but not by sex, and $\mathrm{T}$ levels vary by sex, but not by month (Gonzalez-Gomez et al., 2013), so we included month in the CORT models, and sex in the T model. We ran general linear models with either $\mathrm{T}$, baseline CORT, or stress-induced CORT as fixed effects, as well as the interactions between sex and $\mathrm{T}$, or between month and CORT (baseline and stress-induced), and BKA as the dependent variable.

To check the fit of the models, residuals were tested for normality and homoscedasticity. All tests were 2-tailed with a significance level set to $\alpha=0.05$. We used JMP 10.0 (SAS Institute, Cary, NC) for all analyses.

\section{Results}

\subsection{Life-history stage and $B K A$}

We found that life-history stage and month were significant factors determining BKA (Table 1). Birds in the category "no molt:no reproduction" had the lowest levels of BKA (Fig. 1) although they differed significantly only from birds in category "molt:no reproduction" (Tukey's HSD $P=0.02$ ). To ascertain if birds that were not engaging in either molt or reproduction differed from all others, we grouped the other categories together and compared birds in "no molt:no reproduction" to those engaged in molt, reproduction or both, and found "no molt:no reproduction" birds had lower BKA than birds exhibiting at least one of those life-history stages $\left(t_{1,89}=2.32, P=0.02\right)$. In an attempt to isolate the effects of molting versus breeding, we ran a model with month, molt (yes/no), reproduction (yes/no), and the interaction between molt and reproduction. Month again was significant $\left(F_{3,89}=4.93\right.$, $P=0.003)$, and the interaction between molt and reproduction was significant $\left(F_{3,89}=4.09, P=0.046\right)$ (Fig. 2$)$.

We found that BKA was lowest during the week-long sampling period in May/June, which was significantly lower than BKA levels in December, March, and October (Tukey's HSD P-values <0.03; Fig. 3). To determine if there were more individuals not engaged in either molt or reproduction in the May/June sampling we period, we ran a Pearson's Chi-square test, but found that there were no

Table 1

Life-history stage and bacteria-killing ability in Zonotrichia capensis.

\begin{tabular}{llllc}
\hline Variable & DF & $F$-value & $\mathrm{Eta}^{2}$ & $P$ \\
\hline Life-history stage & $\mathbf{3 , 8 4}$ & $\mathbf{3 . 2 6}$ & $\mathbf{0 . 0 9 7}$ & $\mathbf{0 . 0 3}$ \\
Sex & 1,84 & 1.58 & 0.015 & 0.21 \\
Month & $\mathbf{3 , 8 4}$ & $\mathbf{7 . 2 9}$ & $\mathbf{0 . 2 1 8}$ & $\mathbf{0 . 0 0 1}$ \\
Body condition & 1,84 & 0.03 & 0.00 & 0.87 \\
Location & 1,84 & 0.42 & 0.005 & 0.53 \\
Life hist. $\times$ sex & 1,84 & 0.63 & 0.019 & 0.6 \\
Life hist. $\times$ body cond. & 3,84 & 2.13 & 0.063 & 0.1 \\
\hline
\end{tabular}

Model output for general linear model examining the relationship between lifehistory stage and bacteria-killing ability (BKA) of blood plasma in Zonotrichia capensis. Life-history stage is composed of four categories: (1) bird not molting and not reproducing, (2) birds molting and not reproducing, (3) birds reproducing and not molting, and (4) birds molting and reproducing. Sex, sampling month, body condition (residuals of body mass over tarsus), and location (one of two valleys in the Atacama Desert of Chile) are included as covariates. Values in bold are those significant at the $P<0.05$ level.

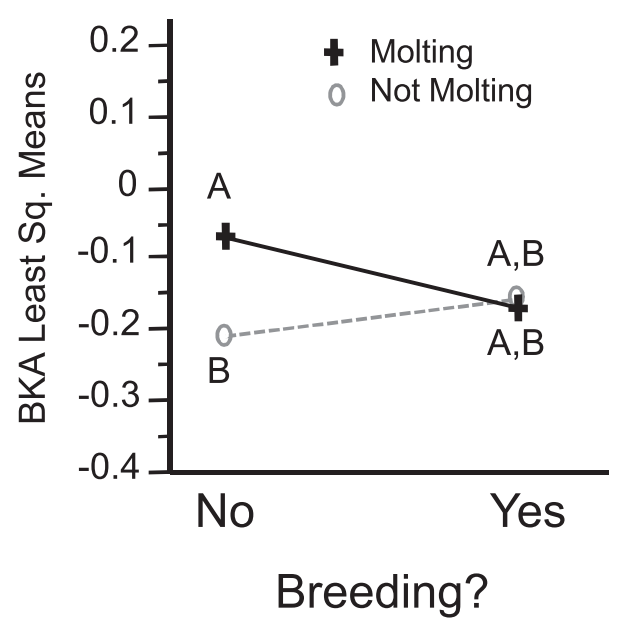

Fig. 2. Least squares means of the bacteria-killing ability (BKA) of Zonotrichia capensis blood plasma illustrating the interaction effects of life-history stage on BKA. Points with different letters are significantly different based on post hoc analyses of the GLM.

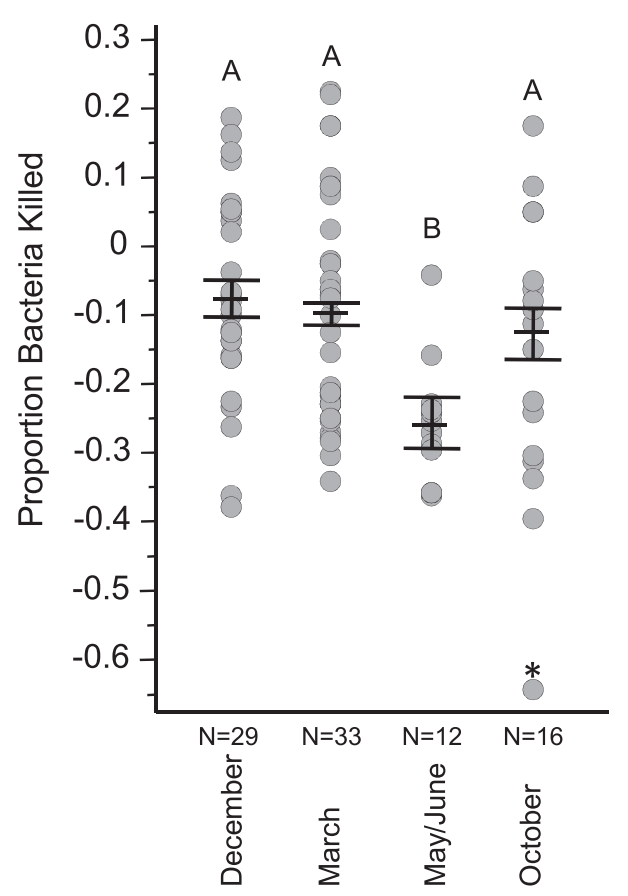

Fig. 3. Bacteria-killing ability (BKA) of Zonotrichia capensis blood plasma over the course of a year. Sampling periods with different letters are significantly different based on post hoc Tukey's HSD. Bars represent mean and standard errors. The data point with the asterisk is a statistical outlier and is not included in analyses or sample sizes denoted.

differences among months in the proportion of birds not engaged in either molt or reproduction (13.8-22.2\%; Pearson Chi-square $(3,90)=0.78, P=0.85)$. This result suggests that month and life-history stage may be separate factors influencing BKA in these birds.

We found no effect of location, sex, or body condition, nor interactions between life-history stage and sex, or between life-history stage and body condition on BKA (Table 1 ).

\subsection{Hormones and $B K A$}

No parameters were significant in the $\mathrm{T}$ model $(P \geq 0.49$; Table 2). In the baseline CORT model, month was again significant 
Table 2

Testosterone and bacteria-killing ability in Zonotrichia capensis.

\begin{tabular}{lllll}
\hline Variable & DF & $F$-value & Eta $^{2}$ & $P$ \\
\hline Testosterone & 1,38 & 0.48 & 0.014 & 0.49 \\
Sex & 1,38 & 0.13 & 0.000 & 0.72 \\
Testosterone $\times$ sex & 1,38 & 0.31 & 0.009 & 0.58 \\
\hline
\end{tabular}

Model output for general linear model examining the relationship between circulating testosterone (T) and bacteria-killing ability (BKA) of the blood plasma in Zonotrichia capensis. Sex is included as a covariate due to documented sex-related differences in T levels in this population (Gonzalez-Gomez et al., 2013).

as a predictor of BKA, baseline CORT itself was not linked to BKA, and there was a non-significant trend for an interaction between month and baseline CORT (Table 3). This trend is driven by a significant positive correlation between baseline CORT and BKA in March $\left(R^{2}=0.23, P=0.025\right)$, and non-significant negative associations between baseline CORT and BKA in the other months. For the model examining BKA and stress-induced CORT levels we found an effect of month, no effect of stress-induced CORT levels themselves, and an interaction effect between month and stress-induced levels of CORT on BKA (Table 4). During March, birds exhibited a negative relationship between stress-induced CORT and BKA $\left(R^{2}=0.17, P=0.07\right)$, whereas there was a positive relationship between stress-induced CORT and BKA in December $\left(R^{2}=0.33, P=0.05\right)$ and no relationships in May/June or October $(P>0.35)$.

To better understand the relationship between CORT levels and BKA, we examined the relationship between baseline CORT and stress-induced CORT in this system. We ran a general linear model in which we included reproduction (yes/no), molt (yes/no), baseline CORT, and month as fixed effects as well as the interaction between baseline CORT and month, and stress-induced CORT as the dependent variable. Both month $\left(F_{3,47}=12.28, P<0.001\right)$ and baseline CORT $\left(F_{1,47}=4.12, P=0.049\right)$ were significant effects, whereas molt, reproduction and the interaction between month and baseline CORT were not $(P$-values $>0.1)$. Stress-induced levels of CORT varied by month with the lowest levels in March, and the highest levels in October, and the overall relationship between baseline CORT and stress-induced CORT was negative (estimate: -0.5 , S.E. $=0.23$ ). Data on general trends of CORT and $\mathrm{T}$ by life-history stage and sampling period for these birds are presented in Gonzalez-Gomez et al. (2013).

\subsection{Parasites}

We found no evidence for infection with either Plasmodium or Haemoproteus parasites in any bird sampled with either screening protocol.

\subsection{Population genetic structure}

Of the eight microsatellite markers initially screened, one did not amplify sufficiently (Gf01), one was monomorphic (E11) and two were out of HWE (Gf06, F11). Therefore, all analyses were performed using three (in the case of AMOVA due to missing data for $\mathrm{C02}$ ) or four loci (all other analyses). No linkage disequilibrium was detected and no loci showed any signature of null alleles. Overall, we detected 23 alleles in 40 Z. capensis individuals ( 22 from Azapa, 18 from Lluta) after removing samples with singleton alleles. Allele numbers per locus ranged from three (Lox1) to nine (G03). Rarefied allelic richness (calculated based on 16 individuals) averaged over all loci was 4.87 for the Azapa population and 5.17 for Lluta population. Two private alleles were found in each population (Lox1: 271, Azapa; G03: 245, Lluta; C02: 268, Lluta; C02: 284, Azapa). Nei's genetic diversity, $\mathrm{H}$, was 0.651 for the Azapa
Table 3

Baseline corticosterone and bacteria-killing ability in Zonotrichia capensis.

\begin{tabular}{lllll}
\hline Variable & DF & $F$-value & Eta $^{2}$ & $P$ \\
\hline Baseline CORT & 1,49 & 0.3 & 0.004 & 0.59 \\
Month & $\mathbf{3 , 4 9}$ & $\mathbf{4 . 8 9}$ & $\mathbf{0 . 2 1 4}$ & $\mathbf{0 . 0 0 5}$ \\
Baseline CORT $\times$ month & 3,49 & 2.62 & 0.115 & 0.06 \\
\hline
\end{tabular}

Model output for general linear model examining the relationship between baseline corticosterone (CORT) and bacteria-killing ability (BKA) of the blood plasma in Zonotrichia capensis. Month is included as a covariate due to documented sampling month-related differences in baseline CORT levels in this population (GonzalezGomez et al., 2013). Values in bold are those significant at the $P<0.05$ level.

Table 4

Stress-induced corticosterone and bacteria-killing ability in Zonotrichia capensis.

\begin{tabular}{lllll}
\hline Variable & DF & $F$-value & Eta $^{2}$ & $P$ \\
\hline Stress-induced CORT & 1,49 & 0.17 & 0.002 & 0.69 \\
Month & $\mathbf{3 , 4 9}$ & $\mathbf{2 . 8 3}$ & $\mathbf{0 . 1 3}$ & $\mathbf{0 . 0 4 9}$ \\
Stress CORT $\times$ month & $\mathbf{3 , 4 9}$ & $\mathbf{3 . 0 3}$ & $\mathbf{0 . 1 4}$ & $\mathbf{0 . 0 4}$ \\
\hline
\end{tabular}

Model output for general linear model examining the relationship between stressinduced corticosterone (CORT) and bacteria-killing ability (BKA) of the blood plasma in Zonotrichia capensis. Month is included as a covariate due to documented sampling month-related differences in stress-induced CORT levels in this population (Gonzalez-Gomez et al., 2013). Values in bold are those significant at the $P<0.05$ level.

population and 0.537 for the Lluta population. Marginally significant genetic differentiation was detected between Azapa and Lluta based on a $F_{\mathrm{ST}}$ value of $0.033(P=0.05)$. The AMOVA revealed that $95.93 \%$ of the genetic variation was partitioned within populations while $4.07 \%$ of the genetic variation was partitioned among populations (AMOVA, $P=0.02$ ). The results from the AMOVA must be interpreted with caution because the sample sizes are small and only three loci were used in the analysis. The Bayesian clustering analysis detected no genetic subdivision; one population that includes both Azapa and Lluta individuals was most likely based on the analysis of the second order rate of change in posterior probabilities between runs of different $k$.

\section{Discussion}

In contrast to our prediction, we found that birds not engaged in either molt or breeding had the lowest BKA, and that over the course of the year, BKA was lowest in the sampling period week of May/June. Among birds that were not breeding, those that were engaged in molt had higher BKA, whereas there was no difference between molting and non-molting birds that were also breeding. We predicted a stronger trade-off between BKA and reproduction, but neither reproduction nor molt was a significant predictor of BKA. Molt appeared to have a larger effect, but it was the lack of molt and reproduction that was significant. The pattern of low BKA in birds not molting or breeding may be a product of low quality and/or poor condition birds being unable to invest resources in reproduction, molt, or aspects of immune function. Conversely, high quality birds may be able to invest in multiple life-history stages and BKA simultaneously (Wilcoxen et al., 2010b; sensu Hill, 2011). Data from our previous study bolster that argument; we found that "no molt-no reproduction" birds had the lowest body condition, whereas those engaging in both molt and reproduction had the highest (Gonzalez-Gomez et al., 2013). We did not find a relationship between body condition and BKA in this study, but the general trends suggest that a bird's condition shapes its capacity for investing in different life-history stages. In addition, if parasite pressure in general is reduced in desert environments, birds may cap their investment in immune function at relatively modest levels (Horrocks et al., 2012a), and there may not be much variation above a certain threshold. If birds in all but the worst 
condition can allocate sufficient resources to meet this level, we would not expect to see a correlation between condition and immune function, but rather a threshold type relationship. In support of this idea we found that birds not breeding and not molting had significantly lower BKA than birds in the other three life-history categories, but that there were no differences among those other three categories.

Furthermore, we found no evidence for infection with blood parasites using two techniques to screen the blood samples. These results indicate that $Z$. capensis in these valleys are mostly or entirely free from haemosporidian blood parasites, and may be under relaxed blood parasite pressure. These results are in line with the only other work conducted on avian blood parasites in this area to our knowledge, in which they found no cases of haemosporidian blood parasites in the cinereous conebill (Martinez et al. unpublished data). These results are likely a product of low vector density in the area, either as a result of the surrounding desert habitat (sensu Valera et al., 2003) or high levels of pesticide use in the valleys (P.L.G.-G. pers. obs). If the prevailing arid conditions of the surrounding matrix influence the parasitological fauna in the valleys, it is likely that these birds experience a general reduction in parasite pressure, including reduced bacterial pathogen pressure (Horrocks et al., 2012b). In contrast to the Horrocks et al. (2012b) study, however, in which they found that immune indices were more strongly linked to microbial abundance rather than life-history, we found that BKA was linked to life-history stage. We did not assess microbial load, however, and the seasonal variation we found in BKA could reflect seasonal variability in microbial abundance (sensu Horrocks et al., 2012b).

In addition to affecting BKA levels, sampling month had a large impact on both baseline and stress-induced levels of CORT. These monthly differences coincide with some general trends in life-history stage, but life-history stage does not explain the complete picture. For example, in March, most birds were engaged in molt, and most down-regulated their stress-responsiveness. But birds not molting also down-regulated their stress-responsiveness at this time (Gonzalez-Gomez et al., 2013). These results suggest that the birds may still be tuned to some circannual patterns that influence HPA-axis activity. The fact that this down-regulation occurs independent of molt in a proportion of the birds, and also that many birds engage in molt without down-regulating HPA-axis activity, suggests that these birds have some level of plasticity in coordinating life-history stage with HPA-axis activity. Alternatively, these could be fixed traits that vary among individuals in the population.

This variation in HPA-axis activity may help explain the different relationships among BKA and CORT levels. Baseline CORT levels and BKA have each been positively linked to fitness parameters (for CORT see Bonier et al., 2009, for BKA see Wilcoxen et al., 2010a; Merrill et al., 2014), and we found a positive relationship between these two parameters in March. The general direction of the relationship reversed for the other months, however, suggesting one of two scenarios: (1) baseline CORT is not directly regulating BKA in these birds, but is indirectly linked to BKA via other regulatory pathways, or (2) that baseline CORT does influence BKA, but the relationship is dose and/or context dependent. Additionally, seasonal changes in corticosteroid binding globulin (CBG) levels or the density of mineralocorticoid and glucocorticoid receptors (MR and GR) could affect these relationships (Breuner and Orchinik, 2001; Wada et al., 2006). Variation in CBG levels would impact the amount of free CORT in circulation, and the variation in free CORT (rather than total CORT) might be driving the observed changes (sensu Mendel, 1989). Changes in MR and GR density could also affect the direction of the relationship between baseline CORT and BKA as the relative occupancy of MR and GR changes. A decrease in MR density should result in higher occupancy of GR, which could lead to a more "stress-type" of relationship between CORT and BKA (e.g., negative relationship). The flipped relationships between stress-induced CORT and BKA are likely bi-products of the generally negative associations between baseline CORT and stress-induced CORT rather than differences in the physiological changes associated with increased CORT levels due to the fact that BKA levels were collected from baseline blood samples.

Location was not a significant factor in our analyses of life-history stage and investment in BKA, but we did find some evidence for weak population genetic structure between the two breeding groups of $Z$. capensis. The $F_{\mathrm{ST}}$ value between Azapa and Lluta valleys was marginally significant, and the AMOVA indicated a low, but significant amount of among-population differentiation. However, the Bayesian clustering method did not support differentiation of two populations. These results suggest that the two breeding groups are neither entirely isolated from one another, nor that they experience high levels of dispersal between them even though they are separated by only $25 \mathrm{~km}$. Barriers to dispersal can be subtle; an animal may not cross a landscape even if it is physically capable of doing so, particularly if that landscape is unsuitable for breeding (reviewed in Harris and Reed, 2002).

At this stage we cannot determine whether the differences between locations we documented previously in the proportion of individuals engaged in both molt and reproduction is based on underlying genetic differences, a response to local environmental conditions, or some combination of the two. Mark-recapture methods of nestlings, radio telemetry approaches, or both could be employed to help answer this question. In addition, following these birds would provide critical information on the long-term ramifications of the sparrows' life-history strategies. We would want to follow these birds for multiple years to assess whether they exhibit longer-term trade-offs between current and future reproduction, or whether birds that exhibit overlap in our study are indeed "high quality" individuals (sensu Wilcoxen et al., 2010b) and are capable of investing in multiple life-history stages repeatedly. These data would provide important insight into the fitness consequences of the different strategies we have observed in these groups of sparrows.

\section{Conclusions}

Species that overlap between distinct life-history stages (e.g., molt and reproduction) provide a natural system to explore the mechanisms shaping life-history strategies. This work examining the relationships among molt, reproduction, and parasite defenses in a highly stable environment provides insight into how organisms allocate resources among potentially competing life-history stages. Our data suggest that the pattern of investment may be dependent upon the individual's condition; those in good condition can allocate resources to molt, reproduction and immune defenses, whereas those in poor condition cannot. Many intrinsic and extrinsic factors can influence the ability of an organism to allocate resources among competing life-history stages, including underlying genetic quality, maternal effects, competition for, and access to, food or breeding territories, thermal regime, predation risk, and parasite pressure. The rufous-collared sparrows studied for this work may be under relaxed pressure for some of these parameters (e.g., thermal variability, parasite pressure, access to food), which could allow for high and even intermediate quality individuals to invest in multiple expensive life-history stages concurrently.

\section{Acknowledgments}

We thank Jennifer Grindstaff for use of lab space to run the BKA, and we thank Pedro Gallo who kindly allowed us to work on his 
property. Javiera Pantoja and Cristobal Venegas were instrumental in the data collection. The population genetics work was supported by an HHMI Undergraduate Science Education award to Grinnell College. A large proportion of the genotyping was done by I. Levin's Bio240 Animal Behavior students: Marta Andelson, Julia Daniels, Moira Donovan, Evan Griffith, Haley Hajic, Sun Han, Seth Howard, Amanda Hodo, Edith March, Sarah McManis, Natalia Nakaidze, Elle Silverman, Loren Ulloa, and Ian Windham. Funded by the Institute of Ecology and Biodiversity (ICM-P05-002, and PFB-23-CONICYT), and Grants FONDECYT 1090794, and FONDECYT 1140548 to R.A.V. J.C.W. is grateful for support from the National Science Foundation (Grant No. IOS-0750540) and the Endowed Chair in Physiology, University of California, Davis.

\section{Appendix A. Supplementary data}

Supplementary data associated with this article can be found, in the online version, at http://dx.doi.org/10.1016/j.ygcen.2015.02. 010.

\section{References}

Addis, E.A., Clark, A.D., Wingfield, J.C., 2011. Modulation of androgens in southern hemisphere temperate breeding sparrows (Zonotrichia capensis): an altitudinal comparison. Horm. Behav. 60, 195-201. http://dx.doi.org/10.1016/ j.yhbeh.2011.05.002.

Allander, K., 1997. Reproductive investment and parasite susceptibility in the Great Tit. Funct. Ecol. 11, 358-364. http://dx.doi.org/10.1046/j.13652435.1997.00095.x.

Ardia, D.R., 2005. Tree swallows trade off immune function and reproductive effort differently across their range. Ecology 86, 2040-2046. http://dx.doi.org/ $10.1890 / 04-1619$.

Atkinson, C.T., Dusek, R.J., Lease, J.K., 2001. Serological responses and immunity to superinfection with avian malaria in experimentally-infected Hawaii amakihi. J. Wildl. Dis. 37, 20-27. http://dx.doi.org/10.7589/0090-3558-37.1.20.

Barta, Z., Houston, A.I., McNamara, J.M., Welham, R.K., Hedenström, A., Weber, T.P., Feró, O., 2006. Annual routines of non-migratory birds: optimal moult strategies. Oikos 112, 580-593. http://dx.doi.org/10.1111/j.00301299.2006.14240.x.

Bonier, F., Moore, I.T., Martin, P.R., Robertson, R.J., 2009. The relationship between fitness and baseline glucocorticoids in a passerine bird. Gen. Comp. Endocrinol. 163, 208-213. http://dx.doi.org/10.1016/j.ygcen.2008.12.013.

Breuner, C.W., Orchinik, M., 2001. Seasonal regulation of membrane and intracellular corticosteroid receptors in the house sparrow brain. J. Neuroendocrinol. 13, 412-420.

Breuner, C.W., Wingfield, J.C., Romero, L.M., 1999. Diel rhythms of basal and stress-induced corticosterone in a wild, seasonal vertebrate, Gambel's white-crowned sparrow. J. Exp. Zool. 284, 334-342. http://dx.doi.org/10.1002/ (SICI)1097-010X(19990801)284:3<334::AID-JEZ11>3.0.CO;2-\#.

Buehler, D.M., Piersma, T., Matson, K., Tieleman, B.I., 2008. Seasonal redistribution of immune function in a migrant shorebird: annual-cycle effects override adjustments to thermal regime. Am. Nat. 172, 783-796. http://dx.doi.org/ $10.1086 / 523977$.

Chapman, F.M., 1940. The post-glacial history of Zonotrichia capensis. Bull. Am. Mus. Nat. Hist. 77, 381-438.

Class, A.M., Wada, H., Lynn, S.E., Moore, I.T., 2011. The timing of life-history stages across latitudes in zonotrichia sparrows. Condor 113, 438-448. http:// dx.doi.org/10.1525/cond.2011.100068.

Combes, C., 2001. Parasitism: The Ecology and Evolution of Intimate Interactions. University of Chicago Press.

Davison, F., Kaspers, B., Schat, K.A., 2008. Avian Immunology. Elsevier, London.

Dawson, A., Hinsley, S.A., Ferns, P.N., Bonser, R.H.C., Eccleston, L., 2000. Rate of moult affects feather quality: a mechanism linking current reproductive effort to future survival. Proc. R. Soc. Lond. B Biol. Sci. 267, 2093-2098. http:// dx.doi.org/10.1098/rspb.2000.1254.

Deerenberg, C., Arpanius, V., Daan, S., Bos, N., 1997. Reproductive effort decreases antibody responsiveness. Proc. R. Soc. Lond. B Biol. Sci. 264, 1021-1029. http:// dx.doi.org/10.1098/rspb.1997.0141.

Durrant, K.L., Beadell, J.S., Ishtiaq, F., Graves, G.R., Olson, S.L., Gering, E., Peirce, M.A., Milensky, C.M., Schmidt, B.K., Gebhard, C., Fleischer, R.C., 2006. Avian hematozoa in South America: a comparison of temperate and tropical zones. Ornithol. Monogr. 98-111. http://dx.doi.org/10.2307/40166831.

Earl, D., vonHoldt, B., 2011. STRUCTURE HARVESTER: a website and program for visualizing STRUCTURE output and implementing the Evanno method. Conserv. Genet. Resour. 4, 359-361.

Echeverry-Galvis, M.A., Hau, M., 2012. Molt-breeding overlap alters molt dynamics and behavior in zebra finches, Taeniopygia guttata castanotis. J. Exp. Biol. 215, 1957-1964. http://dx.doi.org/10.1242/jeb.065474.
Echeverry-Galvis, M.A., Hau, M., 2013. Flight performance and feather quality: paying the price of overlapping moult and breeding in a tropical highland bird. PLoS One 8, e61106. http://dx.doi.org/10.1371/journal.pone.0061106.

Ellis, V.A., Merrill, L., Wingfield, J.C., O'Loghlen, A.L., Rothstein, S.I., 2012. Changes in Immunocompetence and other physiological measures during molt in brown-headed cowbirds (Molothrus ater). Auk 129, 231-238. http:// dx.doi.org/10.1525/auk.2012.11215.

Esser, A., 1994. The membrane attack complex of complement - assembly, structure and cytotoxic activity. Toxicology 87, 229-247. http://dx.doi.org/10.1016/0300483X(94)90253-4.

Estades, C.F., Temple, S.A., 1999. Deciduous-forest bird communities in a fragmented landscape dominated by exotic pine plantations. Ecol. Appl. 9, 573-585. http://dx.doi.org/10.2307/2641145.

Evanno, G., Regnaut, S., Goudet, J., 2005. Detecting the number of clusters of individuals using the software STRUCTURE: a simulation study. Mol. Ecol. 14, 2611-2620. http://dx.doi.org/10.1111/j.1365-294X.2005.02553.x.

Excoffier, L., Lischer, H.E.L., 2010. Arlequin suite ver 3.5: a new series of programs to perform population genetics analyses under Linux and Windows. Mol. Ecol. Resour. 10, 564-567. http://dx.doi.org/10.1111/j.1755-0998.2010.02847.x.

Fallon, S.M., Ricklefs, R.E., Swanson, B.L., Bermingham, E., 2003. Detecting avian malaria: an improved polymerase chain reaction diagnostic. J. Parasitol. 89, 1044-1047. http://dx.doi.org/10.1645/GE-3157.

Fecchio, A., Lima, M.R., Svensson-Coelho, M., Marini, M.A., Ricklefs, R.E., 2013. Structure and organization of an avian haemosporidian assemblage in a neotropical savanna in Brazil. Parasitology 140, 181-192. http://dx.doi.org/ $10.1017 /$ S0031182012001412.

Foster, M.S., 1974. A model to explain molt-breeding overlap and clutch size in some tropical birds. Evolution 28, 182-190. http://dx.doi.org/10.2307/2407321.

Gonzalez-Gomez, P.L., Merrill, L., Ellis, V.A., Venegas, C., Pantoja, J.I., Vasquez, R.A., Wingfield, J.C., 2013. Breaking down seasonality: androgen modulation and stress response in a highly stable environment. Gen. Comp. Endocrinol. 191, 112. http://dx.doi.org/10.1016/j.ygcen.2013.05.007.

Goudet, J., 2001. FSTAT, A Program to Estimate and Test Gene Diversities and Fixation Indices. Lausanne University, Laussane, Switzerland.

Gutiérrez, J.R., Meserve, P.L., Kelt, D.A., Engilis, A., Previtali, M.A., Milstead, W.B., Jaksic, F.M., 2010. Long-term research in bosque fray Jorge national park: twenty years studying the role of biotic and abiotic factors in a Chilean semiarid scrubland. Rev. Chil. Hist. Nat. 83, 69-98.

Harris, R.J., Reed, J.M., 2002. Behavioral barriers to non-migratory movements of birds. Ann. Zool. Fenn. 39, 275-290.

Hartley, A.J., Chong, G., Houston, J., Mather, A.E., 2005. 150 Million years of climatic stability: evidence from the Atacama Desert, northern Chile. J. Geol. Soc. 162, 421-424. http://dx.doi.org/10.1144/0016-764904-071.

Hegemann, A., Matson, K.D., Both, C., Tieleman, B.I., 2012. Immune function in a free-living bird varies over the annual cycle, but seasonal patterns differ between years. Oecologia 170, 605-618. http://dx.doi.org/10.1007/s00442-0122339-3.

Hill, G.E., 2011. Condition-dependent traits as signals of the functionality of vital cellular processes. Ecol. Lett. 14, 625-634. http://dx.doi.org/10.1111/j.14610248.2011.01622.x.

Horrocks, N.P.C., Hegemann, A., Matson, K.D., Hine, K., Jaquier, S., Shobrak, M., Williams, J.B., Tinbergen, Joost M., Tieleman, B.I., 2012a. Immune indexes of larks from desert and temperate regions show weak associations with life history but stronger links to environmental variation in microbial abundance. Physiol. Biochem. Zool. 85, 504-515. http://dx.doi.org/10.1086/666988.

Horrocks, N.P.C., Matson, K.D., Shobrak, M., Tinbergen, J.M., Tieleman, B.I., 2012b. Seasonal patterns in immune indices reflect microbial loads on birds but not microbes in the wider environment. Ecosphere 3. http://dx.doi.org/10.1890/ ES11-00287.1.

Hoye, B.J., Buttemer, W.A., 2011. Inexplicable inefficiency of avian molt? insights from an opportunistically breeding arid-zone species, Lichenostomus penicillatus. PLoS One 6, e16230. http://dx.doi.org/10.1371/journal.pone. 0016230.

Jeffery, K.J., Keller, L.F., Arcese, P., Bruford, M.W., 2001. The development of microsatellite loci in the song sparrow, Melospiza melodia (Aves) and genotyping errors associated with good quality DNA. Mol. Ecol. Notes 1, 1113. http://dx.doi.org/10.1046/j.1471-8278.2000.00005.x.

John, J.L., 1994. Nematodes and the spleen: an immunological relationship. Experientia 50, 15-22. http://dx.doi.org/10.1007/BF01992043.

Johnson, E.I., Stouffer, P.C., Bierregaard Jr., R.O., 2012. The phenology of molting, breeding and their overlap in central Amazonian birds. J. Avian Biol. 43, 141154. http://dx.doi.org/10.1111/j.1600-048X.2011.05574.x.

Jones, M.R., Cheviron, Z.A., Carling, M.D., 2013. Spatial patterns of avian malaria prevalence in Zonotrichia capensis on the western slope of the peruvian andes. J. Parasitol. 99, 903-905. http://dx.doi.org/10.1645/12-147.1.

Kalinowski, S.T., 2005. HP-RARE 1.0: a computer program for performing rarefaction on measures of allelic richness. Mol. Ecol. Notes 5, 187-189. http://dx.doi.org/ 10.1111/j.1471-8286.2004.00845.x.

Kelly, C.D., 2011. Reproductive and physiological costs of repeated immune challenges in female Wellington tree weta (Orthoptera: Anostostomatidae). Biol. J. Linn. Soc. 104, 38-46. http://dx.doi.org/10.1111/j.10958312.2011.01714.x.

Klasing, K.C., 2004. The costs of immunity. Acta Zool. Sin. 50, 961-969.

Knowles, S.C.L., Nakagawa, S., Sheldon, B.C., 2009. Elevated reproductive effort increases blood parasitaemia and decreases immune function in birds: a 
meta-regression approach. Funct. Ecol. 23, 405-415. http://dx.doi.org/10.1111/ j.1365-2435.2008.01507.x.

Lachish, S., Knowles, S.C.L., Alves, R., Wood, M.J., Sheldon, B.C., 2011. Fitness effects of endemic malaria infections in a wild bird population: the importance of ecological structure. J. Anim. Ecol. 80, 1196-1206. http://dx.doi.org/10.1111/ j.1365-2656.2011.01836.x.

Little, R.M., Earlé, R.A., 1995. Sandgrouse (pterocleidae) and sociable weavers Philetarius socius lack avian haematozoa in semi-arid regions of South Africa. J. Arid Environ. 30, 367-370. http://dx.doi.org/10.1016/S0140-1963(05)80011-4.

Longmire, J.L., Maltbie, M., Baker R.J., 1997. Use of "lysis buffer" in DNA isolation and its implication for museum collections. Occasional Paper of the Museum of Texas Tech University 163, pp. 1-4.

Maldonado, K., van Dongen, W.F.D., Vasquez, R.A., Sabat, P., 2012. Geographic variation in the association between exploratory behavior and physiology in rufous-collared sparrows. Physiol. Biochem. Zool. 85, 618-624. http:/ dx.doi.org/10.1086/667406.

Martinez-de la Puente, J., Merino, S., Tomas, G., Moreno, J., Morales, J., Lobato, E., Garcia-Fraile, S., Jorge Belda, E., 2010. The blood parasite haemoproteus reduces survival in a wild bird: a medication experiment. Biol. Lett. 6, 663-665. http:// dx.doi.org/10.1098/rsbl.2010.0046.

Matson, K.D., Tieleman, B.I., Klasing, K.C., 2006. Capture stress and the bactericida competence of blood and plasma in five species of tropical birds. Physiol Biochem. Zool. 79, 556-564.

Mendel, C.M., 1989. The free hormone hypothesis: a physiologically based mathematical model. Endocr. Rev 10, 232-274.

Merino, S., Moreno, J., Vasquez, R.A., Martinez, J., Sanchez-Monsalvez, I., Estades, C.F., Ippi, S., Sabat, P., Rozzi, R., Mcgehee, S., 2008. Haematozoa in forest birds from southern Chile: latitudinal gradients in prevalence and parasite lineage richness. Austral Ecol. 33, 329-340. http://dx.doi.org/10.1111/j.14429993.2008.01820.x

Merrill, L., Angelier, F., O'Loghlen, A.L., Rothstein, S.I., Wingfield, J.C., 2012. Sex-specific variation in brown-headed cowbird immunity following acute stress: a mechanistic approach. Oecologia 170, 25-38. http://dx.doi.org/ 10.1007/s00442-012-2281-4.

Merrill, L., O'Loghlen, A.L., Wingfield, John C., Rothstein, S.I., 2013. Immune function in an avian brood parasite and its nonparasitic relative. Physiol. Biochem. Zool. 86, 61-72. http://dx.doi.org/10.1086/668852.

Merrill, L., Levinson, S.D., O'Loghlen, A.L., Wingfield, J.C., Rothstein, S.I., 2014 Bacteria-killing ability is negatively linked to epaulet size, but positively linked to baseline corticosterone, in male red-winged blackbirds (Agelaius phoeniceus). Auk 131, 3-11. http://dx.doi.org/10.1642/AUK-13-020-R1.1.

Merrill, L., Stewart, T.E., Gonzalez-Gomez, P.L., O'Loghlen, A.O., Wingfield, J.C., Ellis V.E., Rothstein, S.I., 2015. Epaulet size and current condition in red-winged blackbirds: examining a semistatic signal, testosterone, immune function, and parasites. Physiol. Biochem. Zool. 88, 11-21. http://dx.doi.org/10.1086/679475.

Miller, A., 1959. Reproductive cycles in an equatorial sparrow. Proc. Natl. Acad. Sci. USA 45, 1095-1100. http://dx.doi.org/10.1073/pnas.45.7.1095.

Miller, A.H., Miller, V.D., 1968. The behavioral ecology and breeding biology of the Andean sparrow, Zonotrichia capensis. Caldasia 10, 83-155.

Millet, S., Bennett, J., Lee, K.A., Hau, M., Klasing, K.C., 2007. Quantifying and comparing constitutive immunity across avian species. Dev. Comp. Immunol. 31, 188-201. http://dx.doi.org/10.1016/j.dci.2006.05.013.

Moore, I.T., Bonier, F., Wingfield, J.C., 2005. Reproductive asynchrony and population divergence between two tropical bird populations. Behav. Ecol. 16, 755-762. http://dx.doi.org/10.1093/beheco/ari049.

Moreno, J., 2004. Moult-breeding overlap and fecundity limitation in tropical birds: a link with immunity? Ardeola 51, 471-476.

Moreno-Rueda, G., /lhword $>2010$. Experimental test of a trade-off between moult and immune response in house sparrows Passer domesticus J. Evol. Biol. 23, 2229-2237. http://dx.doi.org/10.1111/j.1420-9101.2010.02090.x.

Morrison, E.S., Ardia, D.R., Clotfelter, E.D., 2009. Cross-fostering reveals sources of variation in innate immunity and hematocrit in nestling tree swallows Tachycineta bicolor. J. Avian Biol. 40, 573-578. http://dx.doi.org/10.1111/ j.1600-048X.2009.04910.x.

Morton, M.L., 1992. Control of postnuptial molt in the mountain white-crowned sparrow: a perspective from field data. Ornis Scand. 23, 322. http://dx.doi.org/ $10.2307 / 3676656$.

Moyer, B.R., Drown, D.M., Clayton, D.H., 2002. Low humidity reduces ectoparasite pressure: implications for host life history evolution. Oikos 97, 223-228.

Murphy, M.E., 1996. Energetics and nutrition of molt. In: Carey, C. (Ed.), Avian Energetics and Nutritional Ecology. Plenum Press, pp. 158-198.

Nei, M., 1972. Genetic distance between populations. Am. Nat. 106, 283-292.

Nelson, R.J., Demas, G.E., 1996. Seasonal changes in immune function. Q. Rev. Biol. 71, 511-548.

Nilsson, J.-A., Svensson, E., 1996. The cost of reproduction: a new link between current reproductive effort and future reproductive success. Proc. R. Soc. B 263 711-714. http://dx.doi.org/10.1098/rspb.1996.0106.
Novoa, F.F., Veloso, C., LopezCalleja, M.V., Bozinovic, F., 1996. Seasonal changes in diet, digestive morphology and digestive efficiency in the rufous-collared sparrow (Zonotrichia capensis) in central Chile. Condor 98, 873-876. http:// dx.doi.org/10.2307/1369876.

Ochsenbein, A.F., Zinkernagel, R.M., 2000. Natural antibodies and complement link innate and acquired immunity. Immunol. Today 21, 624-630. http://dx.doi.org/ 10.1016/S0167-5699(00)01754-0.

Ots, I., Hõrak, P., 1998. Health impact of blood parasites in breeding great tits. Oecologia 116, 441-448.

Petren, K., 1998. Microsatellite primers from Geospiza fortis and cross-species amplification in Darwin's finches. Mol. Ecol. 7, 1771-1774.

Piertney, S.B., Marquiss, M., Summers, R., 1998. Characterization of tetranucleotide microsatellite markers in the Scottish crossbill (Loxia scotica). Mol. Ecol. 7, $1261-1263$

Poesel, A., Gibbs, H.L., Nelson, D.A., 2009. Twenty-one novel microsatellite DNA loci isolated from the Puget Sound white-crowned sparrow, Zonotrichia leucophrys pugetensis. Mol. Ecol. Resour. 9, 795-798. http://dx.doi.org/10.1111/j.17550998.2008.02182.x.

Pritchard, J.K., Stephens, M., Donnelly, P., 2000. Inference of population structure using multilocus genotype data. Genetics 155, 945-959.

Ricklefs, R.E., Brawn, J., 2013. Nest attentiveness in several neotropical suboscine passerine birds with long incubation periods. J. Ornithol. 154, 145-154. http:// dx.doi.org/10.1007/s10336-012-0880-9.

Schmid-Hempel, P., /lhword> 2003. Variation in immune defence as a question of evolutionary ecology. Proc. R. Soc. Lond. B Biol. Sci. 270, 357-366. http:// dx.doi.org/10.1098/rspb.2002.2265.

Serra, L., Griggio, M., Licheri, D., Pilastro, A., 2007. Moult speed constrains the expression of a carotenoid-based sexual ornament. J. Evol. Biol. 20, 2028-2034. http://dx.doi.org/10.1111/j.1420-9101.2007.01360.x.

Sheldon, B.C., Verhulst, S., 1996. Ecological immunology: costly parasite defences and trade-offs in evolutionary ecology. Trends Ecol. Evol. 11, 317-321. http:// dx.doi.org/10.1016/0169-5347(96)10039-2.

Smith, H.G., Montgomerie, R., 1991. Sexual selection and the tail ornaments of North American barn swallows. Behav. Ecol. Sociobiol. 28, 195-201.

Stearns, S.C., 1992. The Evolution of Life Histories. Oxford University Press.

Svensson, L.M.E., Ricklefs, R.E., 2009. Low diversity and high intra-island variation in prevalence of avian Haemoproteus parasites on Barbados, Lesser Antilles. Parasitology 136, 1121-1131.

Swaddle, J.P., Witter, M.S., Cuthill, I.C., Budden, A., McCowen, P., 1996. Plumage condition affects flight performance in common starlings: implications for developmental homeostasis, abrasion and moult. J. Avian Biol. 27, 103-111. http://dx.doi.org/10.2307/3677139.

Tella, J.L., Blanco, G., Forero, M.G., Gajón, Á., Donázar, J.A., Hiraldo, F., 1999. Habitat, world geographic range, and embryonic development of hosts explain the prevalence of avian hematozoa at small spatial and phylogenetic scales. Proc. Natl. Acad. Sci. USA 96, 1785-1789.

Torres, E., Acevedo, E., 2008. EL problema de salinidad en los recursos suelo y agua que afectan el riego y cultivos en los valles de Lluta y Azapa en el norte de Chile. Idesia 26, 31-44.

Valera, F., Carrillo, C.M., Barbosa, A., Moreno, E., 2003. Low prevalence of haematozoa in Trumpeter finches Bucanetes githagineus from south-eastern Spain: additional support for a restricted distribution of blood parasites in arid lands. J. Arid Environ. 55, 209-213. http://dx.doi.org/10.1016/S01401963(03)00041-7.

Wada, H., Moore, I.T., Breuner, C.W., Wingfield, J.C., 2006. Stress responses in tropical sparrows: comparing tropical and temperate Zonotrichia. Physiol. Biochem. Zool. 79, 784-792. http://dx.doi.org/10.1086/505509.

Watson, M.J., 2013. What drives population-level effects of parasites? meta-analysis meets life-history. Int. J. Parasitol. Parasit. Wild. 2, 190-196. http://dx.doi.org/ 10.1016/j.ijppaw.2013.05.001.

Wilcoxen, T.E., Boughton, R.K., Schoech, S.J., 2010a. Selection on innate immunity and body condition in Florida scrub-jays throughout an epidemic. Biol. Lett. 6, 552-554. http://dx.doi.org/10.1098/rsbl.2009.1078.

Wilcoxen, T.E., Boughton, R.K., Schoech, S.J., 2010b. Older can be better: physiological costs of paternal investment in the Florida scrub-jay. Behav. Ecol. Sociobiol. 64, 1527-1535. http://dx.doi.org/10.1007/s00265-010-0966-4.

Wingfield, J.C., 2005. Flexibility in annual cycles of birds: implications for endocrine control mechanisms. J. Ornithol. 146, 291-304. http://dx.doi.org/10.1007/ s10336-005-0002-z.

Wingfield, J., Vleck, C., Moore, M., 1992. Seasonal-changes of the adrenocortical-response to stress in birds of the sonoran desert. J. Exp. Zool. 264, 419-428. http://dx.doi.org/10.1002/jez.1402640407.

Zera, A.J., Harshman, L.G., 2001. The physiology of life history trade-offs in animals. Annu. Rev. Ecol. Syst. 32, 95-126. http://dx.doi.org/10.1146/ annurev.ecolsys.32.081501.114006. 